Article

\title{
In Vitro Evaluation of Cytotoxicity and Permeation Study on Lysine- and Arginine-Based Lipopeptides with Proven Antimicrobial Activity
}

\author{
Malgorzata Anna Dawgul ${ }^{1, *,+}$, Katarzyna Ewa Greber $^{2,+}{ }^{\dagger}$, Sylwia Bartoszewska ${ }^{1}$, \\ Wioletta Baranska-Rybak ${ }^{3}$, Wieslaw Sawicki ${ }^{2}$ and Wojciech Kamysz ${ }^{1}$ \\ 1 Department of Inorganic Chemistry, Faculty of Pharmacy, Medical University of Gdansk, Hallera 107, \\ 80-416 Gdansk, Poland; sylwiabart@gumed.edu.pl (S.B.); kamysz@gumed.edu.pl (W.K.) \\ 2 Department of Physical Chemistry, Faculty of Pharmacy, Medical University of Gdansk, \\ 80-416 Gdansk, Poland; greber@gumed.edu.pl (K.E.G.); wsawicki@gumed.edu.pl (W.S.) \\ 3 Department of Dermatology, Faculty of Medicine, Medical University of Gdansk, 80-210 Gdansk, Poland; \\ wiolabar@gumed.edu.pl \\ * Correspondence: mdawgul@gumed.edu.pl; Tel.: +48-58-349-1488; Fax: +48-58-349-1624 \\ + These authors contributed equally to this work.
}

Received: 14 November 2017; Accepted: 6 December 2017; Published: 8 December 2017

\begin{abstract}
Owing to their excellent antimicrobial activities with a relatively low cost of production, lipopeptides are being intensively investigated as potential alternatives to popular antimicrobials. However, a critical obstacle for their application is a relatively high toxicity, hence a lot of attention has been paid to designing new molecules with optimal properties. In this study we synthesized the following lipopeptides: $\mathrm{C}_{16}-\mathrm{KK}^{-\mathrm{NH}_{2}}, \mathrm{C}_{16}-\mathrm{K}_{\varepsilon} \mathrm{K}-\mathrm{NH}_{2}, \mathrm{C}_{16}-\mathrm{KKK}-\mathrm{NH}_{2}, \mathrm{C}_{16}-\mathrm{KRK}-\mathrm{NH}_{2}$, $\mathrm{C}_{16}-\mathrm{RR}^{-\mathrm{NH}_{2}}, \mathrm{C}_{16}-\mathrm{RRR}-\mathrm{NH}_{2},\left(\mathrm{C}_{10}\right)_{2}-\mathrm{KKKK}^{-\mathrm{NH}_{2}}$ and $\left(\mathrm{C}_{12}\right)_{2}-\mathrm{KKKK}^{-\mathrm{NH}_{2}}$. Their antimicrobial activity against representative strains of Gram-positive bacteria, Gram-negative bacteria and fungi has been confirmed. The compounds have been evaluated with regard to the safety of their application in dermatology. The cytotoxicity was determined in HaCaT keratinocytes using MTT assay, whereas Strat M membranes placed in Franz diffusion cells were used to assess their ability to skin permeation. The compounds containing one hexadecanoic acid chain turned out to be very toxic towards human keratinocytes, while lipopeptides containing two fatty acid chains (decanoic and dodecanoic) demonstrated much lower cytotoxicity. For the most promising lipopeptide, $\left(\mathrm{C}_{10}\right)_{2}-\mathrm{KKKK}-\mathrm{NH}_{2}$, the measured $\mathrm{IC}_{50}$ on HaCaT keratinocytes was few times higher as compared to MICs obtained for the tested bacteria. Both groups of lipopeptides did not permeate the model membranes and therefore lack of permeation through human skin could be expected. The results of this work encourage further research on the potential application of lipopeptides with two fatty acids as novel antimicrobials.
\end{abstract}

Keywords: lipopeptides; antimicrobial peptides; toxicity; keratinocytes; skin permeation

\section{Introduction}

Antimicrobial peptides (AMPs) are considered a promising alternative to conventional antimicrobials. There are numerous studies confirming their effectiveness against a broad spectrum of drug resistant microbes, activity against microbial biofilms and low rate of microbial resistance development. Despite numerous advantages of AMPs, there are also many limitations for their therapeutic applications. The most significant ones are a relatively low bioavailability and high costs of production [1,2]. A lot of attention has been paid to designing new analogues: shorter compounds containing the sequence crucial for antimicrobial action or designing novel compounds basing on native AMPs as well as new high throughput methods for their assessment [3-5]. To obtain compounds with improved stability, 
several approaches have been applied: advanced drug formulation or modification of chemical structure of compounds, such as introduction of D-amino acid or fatty acid residues into the molecule [6,7].

Short lipopeptides are amphipathic, positively charged molecules exhibiting antimicrobial activity of AMPs being less cost- and time-consuming in production. They are composed of short peptide chains containing positively charged amino acids (arginine, lysine, and ornithine) combined with a fatty acid residue (palmitic, myristic, lauric) [8,9].

According to the literature, short lipopeptides exhibit strong antimicrobial activity against a broad spectrum of microorganisms including numerous bacteria and fungi [10].

In this study we synthesized six short lipopeptides composed of short peptide chains (containing lysine and/or arginine residues) combined with hexadecanoic (palmitic) fatty acid and two lipopeptides containing a peptide chain composed of four lysine residues combined with two residues of decanoic (capric) and dodecanoic (lauric) acids. The compounds were subjected to an in vitro evaluation with regard to their potential application in dermatology.

\section{Results}

\subsection{Antimicrobial Activity}

All tested compounds exhibited relatively strong antibacterial and moderate antifungal activities (Table 1). S. aureus was inhibited after application of peptides at a concentration of 2 to $16 \mathrm{mg} / \mathrm{L}$. The most active compound in the MIC assay on $\mathrm{S}$. aureus was $\mathrm{C}_{16}-\mathrm{RRR}-\mathrm{NH}_{2}$, while the lipopeptide $\left(\mathrm{C}_{12}\right)_{2}-\mathrm{KKKK}-\mathrm{NH}_{2}$ exhibited the weakest activity $(\mathrm{MIC}=16 \mathrm{mg} / \mathrm{L})$. For $E$. coli, somewhat higher concentrations of lipopeptides were required (MIC for the majority of compounds extended from 8 to $16 \mathrm{mg} / \mathrm{L}$ ). As in the case of Gram-positive bacteria, the lowest activity was exhibited by a lipopeptide containing two residues of the lauric acid (MIC $=64 \mathrm{mg} / \mathrm{L}$ ). The growth of the representative of fungi, C. albicans, was inhibited by the peptides at significantly higher concentrations. The MICs for the majority of lipopeptides was $128 \mathrm{mg} / \mathrm{L}$, while for the lauric acid derivative it was $256 \mathrm{mg} / \mathrm{L}$. The MBC/MFC values were mostly twice as those of MICs, indicating their bactericidal and fungicidal activities.

Table 1. Minimum inhibitory concentrations (MIC) (mg/L) and minimum bactericidal/fungicidal concentrations (MBC/MFC) (mg/L) of the lipopeptides.

\begin{tabular}{|c|c|c|c|c|c|c|c|}
\hline \multirow[b]{2}{*}{ Compound } & \multicolumn{2}{|c|}{ S. aureus } & \multicolumn{2}{|c|}{ E. coli } & \multicolumn{2}{|c|}{ C. albicans } & \multirow[t]{2}{*}{ Reference } \\
\hline & MIC & MBC & MIC & MBC & MIC & MFC & \\
\hline $\mathrm{C}_{16}-\mathrm{KK}-\mathrm{NH}_{2}$ & 4 & 4 & 8 & 8 & 128 & 128 & [11] \\
\hline $\mathrm{C}_{16}-\mathrm{K} \varepsilon \mathrm{K}-\mathrm{NH}_{2}$ & 8 & 8 & 16 & 32 & 128 & 256 & - \\
\hline $\mathrm{C}_{16}-\mathrm{KKK}-\mathrm{NH}_{2}$ & 4 & 8 & 8 & 16 & 128 & 128 & [11] \\
\hline $\mathrm{C}_{16}-\mathrm{KRK}-\mathrm{NH}_{2}$ & 4 & 16 & 8 & 16 & 128 & 256 & - \\
\hline $\mathrm{C}_{16}-\mathrm{RR}-\mathrm{NH}_{2}$ & 8 & 8 & 16 & 16 & 128 & 256 & - \\
\hline $\mathrm{C}_{16}$-RRR-NH 2 & 2 & 4 & 16 & 16 & 128 & 256 & - \\
\hline$\left(\mathrm{C}_{10}\right)_{2}-\mathrm{KKKK}-\mathrm{NH}_{2}$ & 8 & 16 & 16 & 16 & 128 & 256 & [12] \\
\hline$\left(\mathrm{C}_{12}\right)_{2}-\mathrm{KKKK}-\mathrm{NH}_{2}$ & 16 & 32 & 64 & 64 & 256 & 512 & [12] \\
\hline
\end{tabular}

\subsection{Cytotoxicity towards HaCaT Cells and Permeation Study}

The tested compounds exhibited different cytotoxicity in HaCaT cells depending on their chemical structure.

Derivatives of palmitic acid were very cytotoxic and the measured $\mathrm{IC}_{50}$ value ranged from 1.8 to $7.4 \mathrm{mg} / \mathrm{L}$ (Table 2), which in the case of all lipopeptides was below the lowest microbiologically active concentration. The most toxic peptides were $\mathrm{C}_{16}-\mathrm{KK}-\mathrm{NH}_{2}$ and $\mathrm{C}_{16}-\mathrm{RR}^{-\mathrm{NH}_{2}}$. In this group of compounds, the lowest toxicity displayed a lipopeptide with two lysine residues where the peptide bond was created with the $\varepsilon$-amine group of the second residue of lysine. 
In contrast to lipopeptides with the hexadecanoic acid, the compounds containing two chains of decanoic and dodecanoic acids turned out to be non-toxic towards human keratinocytes at their microbiologically active concentrations. The measured $\mathrm{IC}_{50}$ values for $\left(\mathrm{C}_{10}\right)_{2}-\mathrm{KKKK}-\mathrm{NH}_{2}$ and $\left(\mathrm{C}_{12}\right)_{2}-\mathrm{KKKK}-\mathrm{NH}_{2}$ were $49.4 \mathrm{mg} / \mathrm{L}$ and $42.1 \mathrm{mg} / \mathrm{L}$, respectively. For the first peptide, the toxic concentration is as high as about a few times the MICs of compound obtained using bacterial strains.

During the permeation experiments, none of the tested compounds was found in the acceptor solution. On the basis of the signal to noise ratio, the limit of detection of the compounds was calculated. The minimum detectable concentration was $1 \mathrm{mg} / \mathrm{L}$. Therefore, we can expect that the compounds would not be able to penetrate the stratum corneum at concentrations at which they are harmful to the living keratinocytes.

Table 2. Values of $\mathrm{IC}_{50}(\mathrm{mg} / \mathrm{L})$ and their standard deviations obtained for the tested compounds on HaCaT keratinocytes exposed to their action for $24 \mathrm{~h}$.

\begin{tabular}{|c|c|}
\hline Compound & $\mathrm{IC}_{50} \pm \mathrm{SD}$ \\
\hline $\mathrm{C}_{16}-\mathrm{KK}-\mathrm{NH}_{2}$ & $1.8 \pm 0.2$ \\
\hline $\mathrm{C}_{16}-\mathrm{K} \varepsilon \mathrm{K}-\mathrm{NH}_{2}$ & $7.4 \pm 0.9$ \\
\hline $\mathrm{C}_{16}-\mathrm{KKK}-\mathrm{NH}_{2}$ & $3.2 \pm 0.1$ \\
\hline $\mathrm{C}_{16}-\mathrm{KRK}-\mathrm{NH}_{2}$ & $2.3 \pm 0.4$ \\
\hline $\mathrm{C}_{16}-\mathrm{RR}-\mathrm{NH}_{2}$ & $1.9 \pm 0,3$ \\
\hline $\mathrm{C}_{16}$-RRR-NH ${ }_{2}$ & $3.2 \pm 1.4$ \\
\hline$\left(\mathrm{C}_{10}\right)_{2}-\mathrm{KKKK}-\mathrm{NH}_{2}$ & $49.4 \pm 9.1$ \\
\hline$\left(\mathrm{C}_{12}\right)_{2}-\mathrm{KKKK}-\mathrm{NH}_{2}$ & $42.1 \pm 9.1$ \\
\hline
\end{tabular}

\section{Materials and Methods}

\subsection{Lipopeptide Synthesis}

Lipopeptides were obtained via solid phase synthesis on solid polymer support. For protection of $\alpha$-amino groups, 9-fluorenylmethoxycarbonyl (Fmoc) was applied. The protocol was described in the previous paper [11]. The compounds were purified with reversed phase high-performance liquid chromatography. Their purity and identity were confirmed by RP-HPLC and MALDI-TOF mass spectrometry, respectively. The compounds were obtained in order to assess their toxicity and perform the skin permeation study. Their synthesis was previously described when the compounds were obtained for microbiological studies [12-14]. The sequences and molecular masses of the compounds are presented in the Table 3.

Table 3. Amino acid sequences and molecular masses (Da) of the lipopeptides.

\begin{tabular}{|c|c|c|}
\hline \multicolumn{2}{|c|}{ Amino Acid Sequence of Lipopeptide } & \multirow{2}{*}{$\begin{array}{c}\text { Molecular Mass } \\
511.6\end{array}$} \\
\hline Lipopeptide 1 & $\mathrm{C}_{16}-\mathrm{KK}-\mathrm{NH}_{2}$ & \\
\hline Lipopeptide 2 & $\mathrm{C}_{16}-\mathrm{K}_{\varepsilon} \mathrm{K}-\mathrm{NH}_{2}$ & 511.6 \\
\hline Lipopeptide 3 & $\mathrm{C}_{16}-\mathrm{KKK}-\mathrm{NH}_{2}$ & 639.9 \\
\hline Lipopeptide 4 & $\mathrm{C}_{16}-\mathrm{KRK} \mathrm{NH}_{2}$ & 667.9 \\
\hline Lipopeptide 5 & $\mathrm{C}_{16}-\mathrm{RR}-\mathrm{NH}_{2}{ }^{2}$ & 567.8 \\
\hline Lipopeptide 6 & $\mathrm{C}_{16}$-RRR-NH ${ }_{2}$ & 723.7 \\
\hline Lipopeptide 7 & $\left(\mathrm{C}_{10}\right)_{2}-\mathrm{KKKK}-\mathrm{NH}_{2}$ & 837.5 \\
\hline Lipopeptide 8 & $\left(\mathrm{C}_{12}\right)_{2}-\mathrm{KKKK}-\mathrm{NH}_{2}$ & 893.6 \\
\hline
\end{tabular}

\subsection{Antimicrobial Activity}

The compounds were dissolved in a mixture of dimethyl sulphoxide (DMSO) and phosphate buffer (PBS). The final concentration of DMSO in the inoculated samples did not exceed $10 \%$. It has been confirmed that this concentration of DMSO does not influence the growth of tested microorganisms. Application of $10 \%$ DMSO allowed to obtained solutions of $\mathrm{C}_{16}-\mathrm{KK}^{-\mathrm{NH}_{2}}, \mathrm{C}_{16}-\mathrm{KKK}-\mathrm{NH}_{2}$ and 
$\mathrm{C}_{16}-\mathrm{KRK}-\mathrm{NH}_{2}$ at concentration of $512 \mathrm{mg} / \mathrm{L}$, arginine based lipopeptides precipitated at the highest concentration, while compounds with two residues of fatty acids precipitated at $512 \mathrm{mg} / \mathrm{L}$ and $256 \mathrm{mg} / \mathrm{L}$. For obtained solutions/suspensions the minimum inhibitory concentration (MIC) and minimum bactericidal (MBC) and fungicidal concentrations were determined (MFC). MIC was determined by the serial dilution method on polystyrene 96-well plates with Mueller-Hinton II broth (MHB II) for reference bacterial strains: Staphylococcus aureus (ATCC 25923) and Escherichia coli (ATCC 25922), while for Candida albicans (ATCC 10231), the Sabouraud dextrose broth was applied. The microorganisms were obtained from the Polish Collection of Microorganisms (Wroclaw, Poland). Bacteria were cultured at $37^{\circ} \mathrm{C}$ under aerobic conditions overnight in Brain Heart Infusion broth, centrifuged at $1000 \mathrm{rpm}$ for $8 \mathrm{~min}$, washed thrice with PBS and resuspended in MHB II. Candida albicans was cultured in Sabouraud dextrose broth for $48 \mathrm{~h}$ at $27^{\circ} \mathrm{C}$ under aerobic conditions, centrifuged at $1000 \mathrm{rpm}$ for $8 \mathrm{~min}$, washed thrice with PBS and resuspended in Sabouraud dextrose broth. Bacterial $\left(5 \times 10^{5} \mathrm{CFU} / \mathrm{mL}\right)$ and fungal $\left(5 \times 10^{4} \mathrm{CFU} / \mathrm{mL}\right)$ suspensions were exposed to lipopeptides applied at graded concentrations (range $1-512 \mathrm{mg} / \mathrm{L}$ ) for $18 \mathrm{~h}$ at $37{ }^{\circ} \mathrm{C}$ under aerobic conditions (bacteria) and $48 \mathrm{~h}$ at $27^{\circ} \mathrm{C}$ under aerobic conditions (fungi). MIC was taken as the lowest concentration at which no visible growth of bacteria/fungi was observed. MBC and MFC were determined using MH II agar and Sabouraud Dextrose agar, for bacteria and fungi respectively. The contents of wells with MICs and two subsequent higher concentrations were transferred to agar plates and cultivated for $18 \mathrm{~h}$ at $37^{\circ} \mathrm{C}$ under aerobic conditions (bacteria) and $48 \mathrm{~h}$ at $27^{\circ} \mathrm{C}$ under aerobic conditions (fungi). The MBC and MFC were taken as the lowest concentrations at which no colony forming units were found. All tests were performed in triplicate.

\subsection{Cell Line, Culture Conditions and Cytotoxicity Assay}

HaCaT cells were obtained from American Type Culture Collection (ATCC). Cells were cultivated in Dulbecco's modified Eagle Medium (Invitrogen) with 10\% fetal bovine serum in humidified incubator at $39{ }^{\circ} \mathrm{C}$ in $5 \% \mathrm{CO}_{2}$ and cultured in 96-well plates and allowed to grow to $60-70 \%$ confluence prior to the start of the experiments.

The MTT assay is a colorimetric technique for assessing cell metabolic activity based on $\mathrm{NAD}(\mathrm{P}) \mathrm{H}$-dependent cellular oxidoreductase enzymes activity that, under defined conditions, reflects the number of viable cells present. Viable cells reduce the tetrazolium dye MTT 3-(4,5-dimethylthiazol-2-yl)-2,5-diphenyltetrazolium bromide to its insoluble formazan, which has a purple colour. The colour intensity reflects the number of live cells and can be measured spectrophotometrically. Briefly, one day after culturing 500 cells per well, different concentrations of compounds were applied. After a 24-h incubation with the specified compounds, a medium containing $1 \mathrm{mg} / \mathrm{mL}$ MTT was added to the cells (HaCaT keratinocytes) up to a final concentration of $0.5 \mathrm{mg} / \mathrm{mL}$ and incubated at $37^{\circ} \mathrm{C}$ for $4 \mathrm{~h}$. The medium was then aspired, and the formazan product was solubilized with DMSO. The absorbance at $630 \mathrm{~nm}$ (background absorbance) was subtracted and absorbance measured at $570 \mathrm{~nm}$ for each well. There were 6 replicates for each tested concentration. All experiments were repeated at least twice. The resulting $\mathrm{IC}_{50}$ values were calculated with a GraFit 7 software (v. 7.0, Erithacus, Berkley, CA, USA).

\subsection{Permeation Study}

The study was performed on Strat M membranes (Merck, Milipore, Burlington, MA, USA) placed in Franz diffusion cells (SES, Bechenheim, Germany). The compounds at concentrations of $1000 \mathrm{mg} / \mathrm{L}$ in ethanol-water solution $(20 \% \mathrm{~m} / \mathrm{m})$ were added on the surface of the membranes $\left(1.12 \pm 0.03 \mathrm{~cm}^{2}\right)$ and incubated for $24 \mathrm{~h}$. The acceptor solution was the phosphate buffer of $\mathrm{pH} 7.4(\mathrm{~V}=3.79 \pm 0.03 \mathrm{~mL})$. The samples (200 $\mu \mathrm{L}$ of acceptor solution) were taken after $0.5,1,2,4,8,12$ and $24 \mathrm{~h}$ of incubation at $32 \pm 1{ }^{\circ} \mathrm{C}$. The samples were analyzed by RP-HPLC with a linear gradient $2-98 \%$ of solvent $B$ in solvent A in 20 min, eluents: (A) $0.1 \%$ trifluoroacetic acid (TFA) in water, (B) $0.1 \%$ TFA in acetonitrile (ACN), flow rate: $2.0 \mathrm{~mL} / \mathrm{min}$, UV detection: $214 \mathrm{~nm}$, column: Chromolith Performance C18e $4.6 \mathrm{~mm} \times 100 \mathrm{~mm}$. 
A calibration curve was based on peak area measurements of lipopeptide solutions with concantrations ranging $0.01 \div 10.000 \mathrm{mg} / \mathrm{mL}$ with $\mathrm{R}^{2} \geq 0.9991$. The limit of detection (LOD) for tested peptides was found to be around $1.00 \mu \mathrm{g} / \mathrm{mL}$; the limit of reasonable quantification (LOQ) was set at $3.00 \mu \mathrm{g} / \mathrm{mL}$.

\section{Discussion}

Since the introduction of lipopeptides as a potential alternative to available antimicrobials, they have become a topic of intensive research around the globe. Excellent antimicrobial activities with relatively low production costs have drawn the attention of many research groups to investigate lipopeptides as a potential alternative for antibiotic therapy. Numerous studies focusing on their antimicrobial activities and designing molecules with optimal properties have been conducted.

$\mathrm{C}_{16}-\mathrm{KK}-\mathrm{NH}_{2}$ belongs to a group of the extensively studied compounds. In the so far performed studies, the peptide demonstrated high antimicrobial activity against Gram-positive cocci, including antibiotic-resistant strains [13]. Our previous research on palmitic acid derivatives revealed their high effectiveness against biofilm formed by the clinical strains of Staphylococcus aureus, comparable to that of vancomycin [14]. Moreover, the $\mathrm{C}_{16}-\mathrm{KK}^{-\mathrm{NH}_{2}}$ peptide enhanced the activity of the antibiotic used in prophylaxis of vascular graft infection in the rat model [15]. Serrano et al. synthesized short-sequence peptides containing alanine, glycine, leucine and lysine combined with palmitic acid and demonstrated their strong activity against the strains of $S$. aureus, both MSSA as well as MRSA [16]. Similar activity was presented by lipopeptides composed of tryptophan and ornitine residues combined with capric, caproic, caprylic, lauric, myristic and palmitic acids [17]. Combination of lauric acid with short sequences composed of ornithine and cysteine resulted in a high anti-staphylococcal activity against clinical strains [14]. Application of another lipopeptide based on lauric acid, $\mathrm{C}_{12}-\mathrm{CKK}-\mathrm{NH}_{2}$, in combination with daptomycin reduced the development of resistant strains of Enterococcus faecalis [18]. In our previous study, peptides $\mathrm{C}_{16}-\mathrm{KK}-\mathrm{NH}_{2}$ and $\mathrm{C}_{16}-\mathrm{RR}_{-} \mathrm{NH}_{2}$ did not induce the development of resistance by $S$. aureus strains isolated from patients with atopic dermatitis [19]. Those findings support the hypothesis about the low risk of microbial resistance development and membrane related mechanism of action proposed for lipopeptides [9]. In our study, the lipopeptides demonstrated relatively high antimicrobial activities and moderate anti-fungal activities.

The results of the MTT assay obtained in this study indicate high toxicity of lipopeptides containing one palmitic acid chain. This contradicts the previously advanced hypotheses about the selectivity of antimicrobial peptides. According to some authors, peptides designed based on naturally occurring compounds in human organisms are expected to be safe to human cells and their selectivity results from the presence of cholesterol and arrangement of lipids in the eukaryotic cell membrane $[20,21]$. Our results suggest non-selective membrane activity of palmitic acid derivatives. In the previous study, peptide $\mathrm{C}_{16}-\mathrm{KK}^{-\mathrm{NH}_{2}}$ also exhibited a negative influence on proliferation and viability of human keratinocytes at very low concentrations (from $1 \mathrm{mg} / \mathrm{L}$ ) [22]. There is no data on cytotoxicity of remaining palmitic acid based lipopeptides towards $\mathrm{HaCaT}$ cells, but their toxicity towards eukaryotic cells had been confirmed previously by hemolytic assays. The lipopeptides disrupt the membranes of red blood cells once they are exposed to the compounds at concentrations close to their MICs $[9,11]$. Those findings and our results are not encouraging for continued research on this group of lipopeptides and their potential application in the therapy of infections. However, the results of the permeation study allow to expect that the compounds could be applied on intact skin without the risk of harm to living deeper layers of skin or systemic adverse effects. The used synthetic membranes are composed of two layers of polyethersulfone which are more resistant to diffusion and one layer of polyolefin characterized by an enhanced permeability. The polymeric layers create a porous structure with an increasing size of pores and permeability mimicking human skin. The results obtained previously by the producer confirm a high correlation of the results obtained with Strat $\mathrm{M}$ membranes and human skin in comparison to animal skin models [23]. Therefore, the lack of penetration through human skin after topical application of the peptides can be expected. Based on the obtained results and the data from previous studies, we suggest that lipopeptides containing arginine 
and lysine residues combined with palmitic acid could be further tested for their potential application as topical treatment for $S$. aureus carriage. Moreover, it is worth mentioning that a successful in vivo study on $\mathrm{C}_{16}-\mathrm{KK}_{-} \mathrm{NH}_{2}$ has been performed. Its effectiveness in the prevention of staphylococcal biofilm infection in a rat model has been confirmed [14]. Therefore, it can be hypothesized that the cytotoxity of the peptides is reduced in physiological environments. It has been found that the toxicity of the peptides is inhibited by the plasma ingredients such as apolipoproteins A-I and B [20,21]. Due to the discrepancies between in vivo and in vitro toxicities, the obtained results do not exclude palmitic acid derivatives from further studies. However, it seems reasonable to focus the attention on the lipopeptides containing two fatty acid chains. For instance, lipopeptide $\left(\mathrm{C}_{10}\right)_{2}-\mathrm{KKKK}-\mathrm{NH}_{2}$ not only presents a high antimicrobial activity against a broad spectrum of bacteria, but also is non-toxic towards HaCaT keratinocytes and human red blood cells at its microbiologically active concentrations [12]. According to the classification of antimicrobial peptides presented by Shai and Abrahami in patent on antimicrobial and anticancer peptides, the compound can be defined as highly active against $S$. aureus and active against $E$. coli [24]. The results of this work encourage continued research on the potential application of lipopeptides as novel antimicrobials. Our further research will focus on this group of compounds as tools for prevention and elimination of bacterial biofilm as well as on designing new analogues with optimal biological properties: high antimicrobial activity and low toxicity towards human cells.

Acknowledgments: The research was supported by a young researchers found from the Medical University of Gdansk (Project No. 01-0185/08/508).

Author Contributions: M.A.D. designed the study, performed the microbiological experiments and permeation study and wrote the paper; K.E.G. designed lipopeptides with two fatty acid chains and performed the synthesis and purification of all tested peptides; S.B. performed the cytotoxicity assay and analyzed results; W.B.-R. contributed materials and analytical tools for permeation study; W.S. helped with preparation of the manuscript for publication; W.K. designed the derivatives of palmitic acid, supervised their synthesis and helped with the preparation of the manuscript for publication.

Conflicts of Interest: The authors declare no conflict of interest.

\section{References}

1. Marr, A.K.; Gooderham, W.J.; Hancock, R.E.W. Antibacterial peptides for therapeutic use: Obstacles and realistic outlook. Curr. Opin. Pharmacol. 2006, 6, 468-472. [CrossRef] [PubMed]

2. Hancock, R.E.W.; Sahl, H.G. Antimicrobial and host-defense peptides as new anti-infective therapeutic strategies. Nat. Biotechnol. 2006, 24, 1551-1557. [CrossRef] [PubMed]

3. Ciura, K.; Dziomba, S.; Nowakowska, J.; Markuszewski, M.J. Thin layer chromatography in drug discovery process. J. Chromatogr. A 2017, 1520, 9-22. [CrossRef] [PubMed]

4. Ciura, K.; Nowakowska, J.; Rudnicka-Litka, K.; Kawczak, P.; Baczek, T.; Markuszewski, M.J. The study of salting-out thin-layer chromatography and their application on QSRR/QSAR of some macrolide antibiotics. Monatshefte Chem. 2016, 147, 301-310. [CrossRef]

5. Ciura, K.; Nowakowska, J.; Kawczak, P.; Greber, K.E.; Markuszewski, M.J. The quantitative structure-retention relationships and quantitative structure-activity relationships study of macrolide antibiotics on micellar thin layer chromatography. Acta Pol. Pharm.-Drug Res. 2017, 74, 1365-1372.

6. McPhee, J.B.; Scott, M.G.; Hancock, R.E.W. Design of host defence peptides for antimicrobial and immunity enhancing activities. Comb. Chem. High Throughput Screen. 2005, 8, 257-272. [CrossRef] [PubMed]

7. Liu, S.; Zhou, L.; Li, J.; Suresh, A.; Verma, C.; Foo, Y.H.; Yap, E.P.; Tan, D.T.; Beuerman, R.W. Linear analogues of human beta-defensin 3: Concepts for design of antimicrobial peptides with reduced cytotoxicity to mammalian cells. ChemBioChem 2008, 9, 964-973. [CrossRef] [PubMed]

8. Avrahami, D.; Shai, Y. A new group of antifungal lipopeptides derived from non-membrane active peptides conjugated to palmitic acid. J. Biol. Chem. 2004, 279, 12277-12285. [CrossRef] [PubMed]

9. Shai, Y.; Makovitzky, A.; Avrahami, D. Host defense peptides and lipopeptides: Modes of action and potential candidates for the treatment of bacterial and fungal infections. Curr. Protein Pept. Sci. 2006, 7 , 479-486. [CrossRef] [PubMed] 
10. Lohan, S.; Cameotra, S.S.; Bisht, G.S. Systematic Study of Non-Natural Short Cationic Lipopeptides as Novel Broad-Spectrum Antimicrobial Agents. Chem. Biol. Drug Des. 2013, 82, 557-566. [CrossRef] [PubMed]

11. Greber, K.E.; Dawgul, M.; Kamysz, W.; Sawicki, W. Cationic net charge and counter ion type as antimicrobial activity determinant factors of short lipopeptides. Front. Microbiol. 2017, 8, 1-10. [CrossRef] [PubMed]

12. Greber, K.E.; Dawgul, M.; Kamysz, W.; Sawicki, W.; Łukasiak, J. Biological and surface-active properties of double-chain cationic amino acid-based surfactants. Amino Acids 2014, 46, 1893-1898. [CrossRef] [PubMed]

13. Kamysz, W.; Silvestri, C.; Cirioni, O.; Giacometti, A.; Licci, A.; Della Vittoria, A.; Okroj, M.; Scalise, G. In vitro activities of the lipopeptides Palmitoyl (Pal)-Lys-Lys- $\mathrm{NH}_{2}$ and Pal-Lys-Lys alone and in combination with antimicrobial agents against multiresistant Gram-positive cocci. Antimicrob. Agents Chemother. 2007, 51, 354-358. [CrossRef] [PubMed]

14. Dawgul, M.; Baranska-Rybak, W.; Kamysz, E.; Karafova, A.; Nowicki, R.; Kamysz, W. Activity of short lipopeptides and conventional antimicrobials against planktonic cells and biofilms formed by clinical strains of Staphylococcus aureus. Future Med. Chem. 2012, 4, 1541-1551. [CrossRef] [PubMed]

15. Cirioni, O.; Giacometti, A.; Ghiselli, R.; Kamysz, W.; Silvestri, C.; Orlando, F.; Mocchegiani, F.; Della Vittoria, A.; Kamysz, E.; Saba, V.; et al. The lipopeptides Pal-Lys-Lys- $\mathrm{NH}_{2}$ and Pal-Lys-Lys soaking alone and in combination with intraperitoneal vancomycin prevent vascular graft biofilm in a subcutaneous rat pouch model of staphylococcal infection. Peptides 2007, 28, 1299-1303. [CrossRef] [PubMed]

16. Serrano, G.N.; Zhanel, G.G.; Schweizer, F. Antibacterial activity of ultrashort cationic lipo-beta-peptides. Antimicrob. Agents Chemother. 2009, 53, 2215-2217. [CrossRef] [PubMed]

17. Laverty, G.; McLaughlin, M.; Shaw, C.; Gorman, S.P.; Gilmore, B.F. Antimicrobial activity of short, synthetic cationic lipopeptides. Chem. Biol. Drug Des. 2010, 75, 563-569. [CrossRef] [PubMed]

18. Cirioni, O.; Kamysz, E.; Ghiselli, R.; Kamysz, W.; Silvestri, C.; Orlando, F.; Rimini, M.; Brescini, L.; Gabrielli, E.; Marchionni, E.; et al. Lipopeptide Laur-CKK-NH 2 dimer preserves daptomycin susceptibility and enhances its activity against Enterococcus faecalis. J. Antimicrob. Chemother. 2011, 66, 859-862. [CrossRef] [PubMed]

19. Dawgul, M.; Barańska-Rybak, W.; Piechowicz, L.; Bauer, M.; Neubauer, D.; Nowicki, R.; Kamysz, W. The antistaphylococcal activity of citropin 1.1 and temporin A against planktonic cells and biofilms formed by isolates from patients with atopic dermatitis: An assessment of their potential to induce microbial resistance compared to conventional antimicrobials. Pharmaceuticals 2016, 9, 1-13.

20. Zasloff, M. Antimicrobial peptides of multicellular organisms. Nature 2002, 415, 389-395. [CrossRef] [PubMed]

21. Lai, Y.; Gallo, R.L. AMPed Up immunity: How antimicrobial peptides have multiple roles in immune defense. Trends Immunol. 2009, 30, 131-141. [CrossRef] [PubMed]

22. Barańska-Rybak, W.; Pikuła, M.; Dawgul, M.; Kamysz, W.; Trzonkoski, P.; Roszkiewicz, J. Safety profile of antymicrobial peptides: Camel, citropin, protegrin, temporin A and lipopeptide on HaCaT keratinocytes. Acta Pol. Pharm.-Drug Res. 2013, 70, 795-801.

23. Available online: http://www.millipore.com/publications.nsf/a73664f9f981af8c852569b9005b4eee/ 1c544b6645c6e4a385257a63005efd7f/\$FILE/PB4013EN00_EM.pdf (accessed on 12 August 2017).

24. Shai, Y.; Abrahami, D. Antimicrobial and Anticancer Lipopeptides, Yustia Patents, No. 8445636. Available online: https: / / patents.justia.com/patent/8445636 (accessed on 6 July 2017).

Sample Availability: Samples of the compounds $\left(\mathrm{C}_{10}\right)_{2}-\mathrm{KKKK}-\mathrm{NH}_{2}$ and $\left(\mathrm{C}_{12}\right)_{2}-\mathrm{KKKK}-\mathrm{NH}_{2}$ are available from the authors.

(C) 2017 by the authors. Licensee MDPI, Basel, Switzerland. This article is an open access article distributed under the terms and conditions of the Creative Commons Attribution (CC BY) license (http:/ / creativecommons.org/licenses/by/4.0/). 